\title{
Characteristics of Patient with Status Epilepticus at the Emergency Department of Sanglah General Hospital
}

\author{
Maria Oktaviany Gabur ${ }^{1}$, I Wayan Widyantara ${ }^{1}$, Anna M.G. Sinardja ${ }^{1}$ \\ ${ }^{1}$ Neurology Department of Medical Faculty of Udayana University, Sanglah General Hospital, Denpasar, Bali \\ Corresponding Author: Maria Oktaviany Gabur
}

\begin{abstract}
Introduction: Status epilepticus is a neurological condition caused by a failure of body mechanism to terminate the seizures or the onset of abnormal seizure activity resulting in prolonged seizure's duration for more than five minutes. The available research data on status epilepticus in Indonesia is still limited. The purpose of this study was to determine the profile of patients with status epilepticus at Sanglah General Hospital from 2020 to 2021.

Methods: This was a descriptive study with a retrospective approach. The study populations were patients with status epilepticus who were treated at Sanglah General Hospital in 20192020 who had no missing data in the medical records.
\end{abstract}

Results: There were 117 patients with status epilepticus, 63 males (53.8\%) and 54 females (46.2\%). There are 41 patients $>60$ years (35\%), general onset in 63 patients (53.8\%), and focal onset in 54 patients (46.2\%). Etiology from cerebral was 68 patients (58.1\%), followed by metabolic in 28 patients (23.9\%). The most common OAE therapy was phenytoin (86.3\%) and the longest length of stay status epilepticus patients was 8 days (55.6\%). Patients with status epilepticus had leukocytosis (73.5\%), increased NLR (66.7\%), and decreased mean platelet volume (53.8\%).

Conclusion: The highest incidence of status epilepticus is in women, above 60 years, general onset type of seizure, and etiology from cerebral. Initial therapy in 117 patients was intravenous diazepam followed by phenytoin for maintenance. NLR increased in most of the patients showing signs of inflammation which further worsened the patient's outcome with a mortality rate of $47 \%$.

Keywords: Status epilepticus, seizure duration, anticonvulsant, neutrophil-lymphocyte ratio

\section{INTRODUCTION}

Status epilepticus (SE) is a common neurological emergency which requires prompt treatment to reduce morbidity and mortality. ${ }^{1}$ Status epilepticus is defined as sustained seizure, or two or more seizures without restoration of consciousness, lasting longer than 30 minutes. However, status epilepticus is now defined by two-time points, $\mathrm{t} 1$ and $\mathrm{t} 2$, identified as the time at which the seizure is likely to last longer and the time at which the seizure will lead to long-term consequences, respectively; for tonic-clonic seizures, $\mathrm{t} 1$ is 5 minutes and $\mathrm{t} 2$ is 30 minutes; for focal seizure, $\mathrm{t} 1$ is 10 minutes and t2 is > 60 minutes; but for absence seizure (lena), these time points are different or unknown. ${ }^{2}$

The incidence of status epilepticus ranges from 5 to 40 per 100,000 based on several population-based studies with recent meta-analyses reporting an annual incidence of 12.6 per $100,000.4,5,6$ The types of severe and prolonged SE are refractory status epilepticus (RSE) and super refractory status epilepticus (SRSE). RSE occurs in $29 \%-43 \%$ of SE cases and SESR is seen in $12 \%-26 \%$ of SE cases and $13 \%-42 \%$ of RSE cases. ${ }^{5,6}$ 


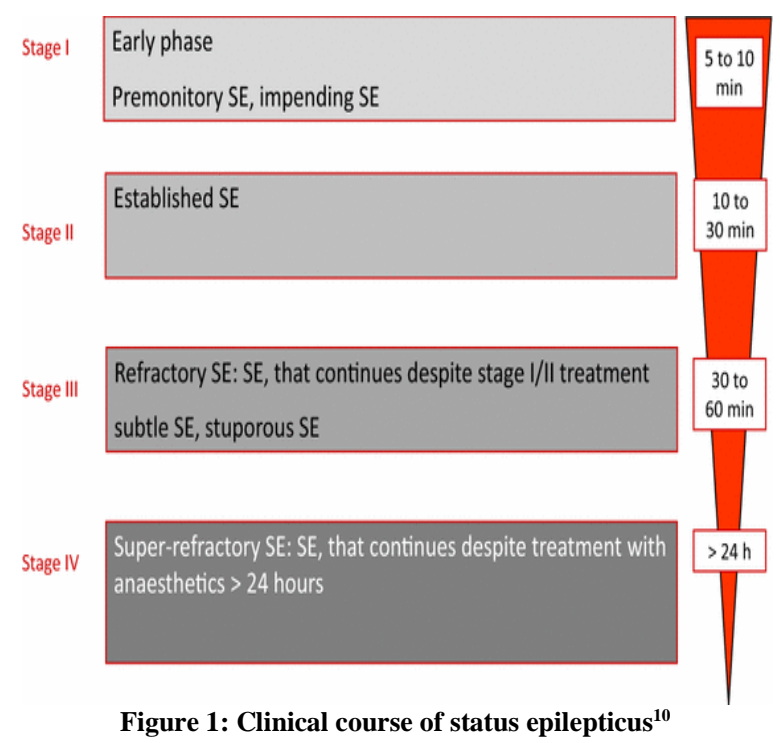

There was no significant difference in the incidence of SE in males and females. Although previous studies had found a greater incidence of status epilepticus in males, ${ }^{12-14}$ recent study estimated that the incidence for both sexes are similar than previously thought (11.1 per 100,000 person-years in females, 11.3 per 100,000 person-years in males). ${ }^{5}$

The annual incidence in the elderly is 27.1 per 100,000 , which is approximately four times higher from non-geriatric adults. $^{2,3}$ The incidence was similar in developing and developed countries. The incidence of status epilepticus appears to peak at older than 50 years (approximately 28.4 per 100,000 per year) and younger than 10 years (14.3 per 100,000 per year) and appears to be higher in African Americans (13.7 per 100,000 per year) compared with whites' people (6.9 per 100,000 per year) and other races (7.4 per 100,000 per year). ${ }^{7}$

The overall case fatality rate is close to $15 \%$, with greater case fatality rates occurring in the elderly (24.9\%) and patients with refractory status epilepticus (33.3\%). ${ }^{5,6}$ The incidence of status epilepticus appears to increase over time. In a study from the US National Hospital Discharge Survey, between 1979 and 2010, the incidence of status epilepticus has increased from 3.5 per 100,000 per year to 12.5 per 100,000 per year but there was no significant change in hospital mortality. ${ }^{7}$
At least half of patients with SE have no history of epilepsy. Acute neurologic impairment and prolonged seizure cause significant variability in clinical presentation. SE is not a disease entity but a symptom with multiple etiologies. $^{2}$

According to the International League Against Epilepsy, the etiology of status epilepticus can be divided into two groups: (1) known or symptomatic and (2) unknown or cryptogenic. The group of symptoms can be further subdivided into acute seizure and remote seizure (seizures that occur more than 1 week or more after a known risk disorder for epilepsy). Seizures can occur long after the disorder, named after a traumatic brain injury or stroke, and progressive. $^{2,3}$ The underlying etiology of status epilepticus often influences the patient's likelihood of mortality. ${ }^{9}$

\section{MATERIAL AND METHODS}

This study was a descriptive study with a retrospective approach to describe patients with status epilepticus in proportions or percentages. The study population was patients with status epilepticus treated at Sanglah General Hospital in 2019-2020 and had complete medical records. The study was conducted from December 2020 to February 2021. Data were collected using patient's medical records, processed using Microsoft Excel, and presented in narration, tables, and figures.

\section{RESULT}

In this study, the number of patients with status epilepticus at Sanglah General Hospital in 2019-2020 was 117 patients, 63 males (53.8\%) and 54 females (46.2\%). It was common in patients more than 60 years (41 patients, 35\%).

Based on Table 1, the most common seizure types were general onset as many as 63 patients (53.8\%) and focal onset as many as 54 patients (46.2\%). Based on the etiology, the highest was cerebral origin (68 patients, 58.1\%), followed by metabolic (28 
Maria Oktaviany Gabur et.al. Characteristics of patient with status epilepticus at the emergency department of Sanglah General Hospital

patients, 23.9\%). The most widely patients with status epilepticus had administered OAE therapy was phenytoin leukocytosis (73.5\%), increased NLR (86.3\%), and the longest length of stay of patients with status epilepticus was 8 days (66.7\%), and decreased mean platelet (55.6\%). Based on the laboratory results, volume (53.8\%) (Figure 1)

Table 1: The characteristics of patients with status epilepticus at Sanglah General Hospital in 2019-2020

\begin{tabular}{|c|c|c|}
\hline Characteristic & Frequency $(n=117)$ & Percentage (\%) \\
\hline \multicolumn{3}{|l|}{ Gender } \\
\hline Female & 54 & 46.2 \\
\hline Male & 63 & 53.8 \\
\hline \multicolumn{3}{|l|}{ Age (years old) } \\
\hline $18-29$ & 19 & 16.2 \\
\hline $30-39$ & 14 & 12.0 \\
\hline $40-49$ & 25 & 21.4 \\
\hline $50-59$ & 18 & 15.4 \\
\hline$>60$ & 41 & 35.0 \\
\hline \multicolumn{3}{|l|}{ Type of seizure } \\
\hline Focal onset & 54 & 46.2 \\
\hline General onset & 63 & 53.8 \\
\hline \multicolumn{3}{|l|}{ Type of etiology } \\
\hline Cerebral & 68 & 58.1 \\
\hline Cardio-respiration \& autonomic & 6 & 5.1 \\
\hline Metabolic & 28 & 23.9 \\
\hline Immunology & 8 & 6.8 \\
\hline And others & 7 & 6.0 \\
\hline \multicolumn{3}{|l|}{ Type of OAE therapy } \\
\hline Stage I & & \\
\hline Diazepam & 117 & 100 \\
\hline Stage II & & \\
\hline Phenytoin & 101 & 86.3 \\
\hline Phenobarbital & 8 & 6.8 \\
\hline Diazepam & 4 & 3.4 \\
\hline Valproic acid & 4 & 3.4 \\
\hline
\end{tabular}

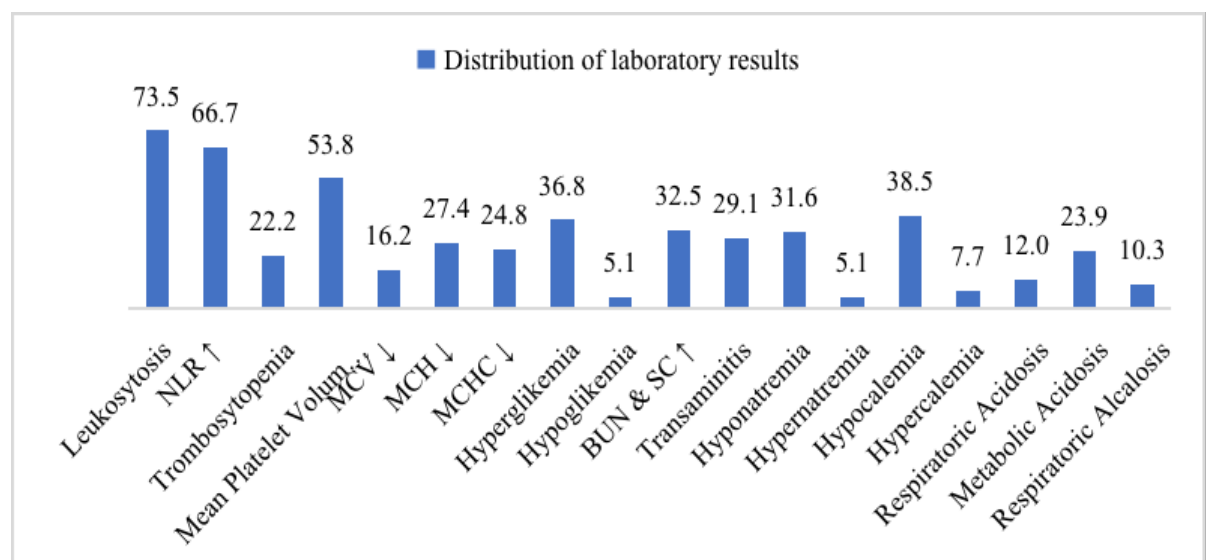

Figure 1: The laboratory results in patients with status epilepticus at Emergency Department of Sanglah General Hospital in 20192020.

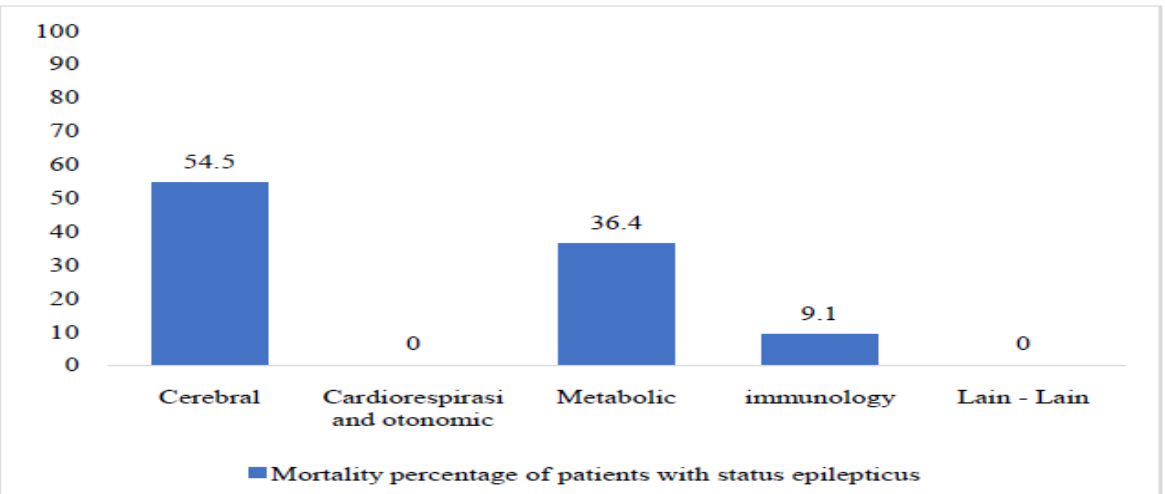

Figure 2: The mortality in patients with status epilepticus based on etiology at Emergency Department of Sanglah General Hospital in 2019-2020. 
Maria Oktaviany Gabur et.al. Characteristics of patient with status epilepticus at the emergency department of Sanglah General Hospital

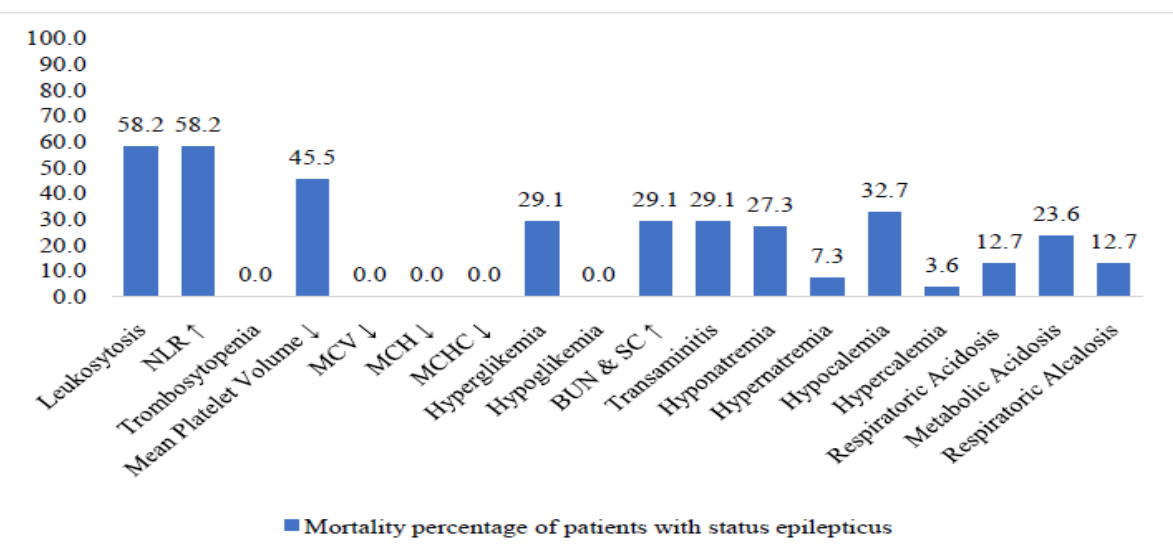

Figure 3: The mortality in patients with status epilepticus based on clinical laboratory results at Emergency Department of Sanglah General Hospital in 2019-2020.

Of all patients with status epilepticus at Sanglah General Hospital from 2019 to 2020, the mortality rate was 55 cases (47\%). Based on the etiology, the highest mortality rate was cerebral causes (54.5\%), followed by metabolic causes (36.4\%) (Figure 2). In addition, $58.4 \%$ mortality of patients with status epilepticus was leukocytosis and an increase in NLR, based on laboratory results.

\section{DISCUSSION}

In this study, it was found that the incidence of females was higher than males, and from various studies, there were no significant differences between males and females, although previous studies found a higher incidence of status epilepticus in males. ${ }^{5}$ The highest incidence of status epilepticus was elderly. The prevalence and incidence of SE were higher in the population over 60 years old than in younger adults. ${ }^{12}$ Various studies suggest that the annual incidence rate in the elderly was 27.1 per 100.000 which is approximately four times that of nongeriatric adults. ${ }^{2,3}$ Incidence increases with age, from 15.5/100.000 for subjects aged $60-69$ years to $25.9 / 100.000$ for those over $80 .^{13}$

The most common etiology in this study was cerebral. The elderly had comorbidities and take many medications for their ailments. A frequent combination of factors, such as metabolic disorders, renal failure, and systemic infection complicates the etiology. ${ }^{11}$ Therefore, SE generally occurs in a multifactorial context, triggered by one or more acute causes in patients with predisposing conditions (non-acute brain pathology and/or associated comorbidities). $\mathrm{SE}$ is often classified as acute or remote. The main causes in the elderly were stroke (acute or remote symptoms, other metabolic causes, AED discontinuation, dementia, brain injury, systemic/CNS infections, alcohol-related, hypoxaemic and undetermined). ${ }^{14}$

Recent guidelines from ILAE (2015) identify etiology as one of four main axes (with clinical semiology, EEG correlation, and age) to characterize SE. ${ }^{15}$ These guidelines divide etiology into two main groups: identified (symptomatic) causes and unidentified causes (cryptogenic). The identified causes were classified in terms of the mode of onset: acute, remote, or progressive etiology. In acute symptomatic $\mathrm{SE}$, the main etiologies were anoxic encephalopathy (20\%), central nervous system (CNS) infection (17\%), and cerebrovascular disease (CVD) (17\%). Among non-induced SE, 20\% were considered progressive and symptomatic, $47 \%$ were remote and $33 \%$ had no identifiable cause. SE is considered an acute symptom when it occurs in the acute phase (within the first seven days) of the onset of head trauma, CNS infection, systemic infection with fever without direct CNS lesions, CVD, toxic encephalopathy, alcohol, or drug withdrawal, and metabolic encephalopathy. The most common metabolic causes were blood glucose 
disturbances (hypoglycemia, diabetic hyperglycemic syndrome), electrolyte imbalance (hypo/hypernatremia, hypo/ hypercalcemia), hyperammonemia, hypoxemia, hyperhomocysteinemia. ${ }^{16}$

The initial therapy for status epilepticus (SE) in our hospital was intravenous diazepam. It is said that the initial period of the status epilepticus management procedure is the period before admission and the first minute of admission to the hospital. The early therapy was important because the risk of developing resistance and nerve damage increases as the duration of SE increases. As a result of several prehospital trials, SE therapy should be initiated in the emergency department, even in the ambulance. ${ }^{17}$ The most important AED in this period is benzodiazepines. Benzodiazepines exhibit anti-epileptic activity through binding to the GABA-A receptor. ${ }^{18}$ After demonstrating the superiority of IV benzodiazepines (clonazepam, lorazepam, and diazepam) over placebo in the cessation of SE, there have been efforts to develop buccal and nasal preparations which could be easily applied in prehospital or even at home. ${ }^{17}$ Diazepam is fat-soluble which rapidly spreads to body tissues and enters the brain tissue. The effectiveness of an intravenous and rectal preparation for adults and pediatrics with SE had been demonstrated in a study by Cereghino et al. ${ }^{19}$

In the next stage of seizures, our selection of OAEs were phenytoin, phenobarbital, valproic acid. This stage is defined as SE that does not improve with first-line benzodiazepine therapy and lasts more than 20 minutes. ${ }^{17}$ Phenytoin (Diphenylhydantoin) has been used in the treatment of SE for 50 years, in the correct dose for the last 20 years. It is not recommended in the early stages of $\mathrm{SE}$ because of the low infusion rate (50 $\mathrm{mg} / \mathrm{min}$ ) and the slow onset. Phenytoin should be administered at a dose of 15$18 \mathrm{mg} / \mathrm{kg}$, and blood phenytoin levels should be targeted to $20-30 \mathrm{~g} / \mathrm{mL}$. However, the side effect should be monitored, namely hypotension and cardiac arrhythmias, especially in older patients and those with premorbid heart disease. For this reason, cardiac monitoring during administration and slower infusion rates at lower doses (15 $\mathrm{mg} / \mathrm{kg}$ ) are required. ${ }^{17}$ Valproic acid (VPA) is effective in all types of seizures and is the most widely prescribed AED. in the world. ${ }^{17,20}$ The recommended effective dose is $15-45 \mathrm{mg} / \mathrm{kg}$ bolus $(6-10 \mathrm{mg} / \mathrm{kg} / \mathrm{min})$, followed by infusion of $1-3 \mathrm{mg} / \mathrm{kg} / \mathrm{hr}{ }^{20}$ High infusion rate, such as $40 \mathrm{mg} / \mathrm{kg} / \mathrm{min}$, have also been reported in the ICU. It has no sedative effect. Dizziness, thrombocytopenia, and mild hypotension have been reported in less than $10 \%$ of patients. ${ }^{17,20}$ Phenobarbital is not the first choice due to its respiratory depressant effect is higher. The most important disadvantages are sedation, respiratory depression, and hypotension. The recommended dose is $10-$ $20 \mathrm{mg} / \mathrm{kg}$. It is recommended to be administered at a dose of $100 \mathrm{mg} / \mathrm{min}$ for 7 minutes with close monitoring of breathing and blood pressure. ${ }^{17}$

Most of the patients in this study had leukocytosis, high NLR ratio, and low MPV. It is indicated that there is a significant relationship between epileptic seizures and systemic inflammation and it has been demonstrated that systemic inflammation can trigger epileptic activity by worsening blood-brain barrier function. ${ }^{21}$

The importance of leukocytes has been investigated in the pathophysiology of epilepsy in several studies. Johnson et al. showed that neutrophil infiltration occurred in the brain of injured mice after exposure to seizurogenic nerve agents. ${ }^{21}$ Ozdemir et al. found that the mean NLR values in the acute period of SE were significantly higher than the subacute period and control group values. This suggested that inflammation, particularly neutrophil-associated inflammation, maybe an etiology of CSE. NLR may be an effective and inexpensive marker for evaluating inflammation in SE. The most important limitations of the study were its retrospective nature and the fact that the investigators did not evaluate the 
association between SE duration and NLR value. They suggest that further studies should be carried out to assess the potential role of albumin, neutrophils, and lymphocytes in SE. ${ }^{22}$

The mortality rate of patients in this study was quite high, 55 people, $47 \%$ of all cases in 2 years. Predicting the outcome of the incidence of status epilepticus is not easy and depends on multiple factors such as demographic, pre-OAE clinical features, duration of seizures, etiology, laboratory results, EEG features, therapy, and complications.

Status Epilepticus Severity Score (SESS) and Epidemiology-based Mortality Score in SE (EMSE) were two scores that can predict the outcome of SE. Both are easy to apply. The SESS is good for predicting poor outcome with a limitation especially in patients over 65 years of age without a previous history of epilepsy. In contrast, EMSE is good at detecting poor outcomes and eligible for and individual risk assessment and risk stratification in intervention studies. ${ }^{23}$

From various studies, the role of gender in SE-related mortality remains unclear due to the inconsistency of data obtained from the other population-based studies and systematic reviews. Older age was associated with either a higher incidence of SE or independently associated with a higher probability of death. ${ }^{24}$ Changes in the level of consciousness can indicate the severity of SE, in which the low level of consciousness was associated with largely unfavorable outcomes despite intensive therapy, and low levels of consciousness at the onset of SE were associated with poorer outcomes. ${ }^{25}$

\section{CONCLUSION}

The highest incidence of status epilepticus is found to be in women above 60 years, with general onset type of seizure, with cerebral etiology. NLR increased in most of the patients showing signs of inflammation which further worsened the patient's outcome with a mortality rate of $47 \%$

Conflict of Interest: The authors declare that they have no conflict of interest.

Acknowledgement: None

Source of Funding: None

Ethical Approval: Approved

\section{REFERENCES}

1. Nelson S, Varelas P. Status Epilepticus, Refractory Status Epilepticus, and Super Refractory Status Epilepticus. Continuum Neurocritical Care. 2018;24:1683-1707.

2. Trinka E, Cock H, Hesdorffer D, Rossetti A, Scheffer I, et al. A definition and classification of status epilepticus-Report of the ILAE Task Force on Classification of Status Epilepticus. Epilepsia, 56(10):15151523, 2015. doi: 10.1111/epi.13121

3. Betjemann JP, Lowenstein DH. Status epilepticus in adults. Lancet Neurol 2015; 14(6):615-624. doi:10.1016/S1474-4422 (15)00042-3.

4. R. J. Lv, Q. Wang, T. Cui, F. Zhu, and X. Q. Shao, "Status epilepticus-related etiology, incidence and mortality: a metaanalysis," Epilepsy Research, vol. 136, pp. 12-17, 2017.

5. Tiamkao, S. Pranbul, K. Sawanyawisuth, K. Thepsuthammarat, and Integrated Epilepsy Research Group, “A national database of incidence and treatment outcomes of status epilepticus in Thailand," International Journal of Neuroscience, vol. 124, no. 6, pp. 416-420, 2014.

6. Dham BS, Hunter K, Rincon F. The epidemiology of status epilepticus in the United States. Neurocrit Care 2014;20 (3):476-483. doi:10.1007/ s12028-0139935-x.

7. Brophy GM, Bell R, Claassen J, Alldredge B, Bleck TP, et al. Guidelines for the evaluation and management of status epilepticus. Neurocrit Care 2012;17(1):3-23. doi:10.1007/s12028-012-9695-z.

8. Betjemann JP, Josephson SA, Lowenstein DH, Burke JF. Trends in status epilepticusrelated hospitalizations and mortality. JAMA Neurol 2015;72(6):650-655. doi:10.1001/jamaneurol. 2015.0188. 
9. Gaspard N. Hirsch L, Sculier C, Loddenkemper T, van Baalen A, Lancrenon $\mathrm{J}$, et al. New-onset refractory status epilepticus (NORSE) and febrile infectionrelated epilepsy syndrome (FIRES): State of the art and perspectives. Epilepsia. 2018; 00:1-8. https://doi.org/10.1111/epi.14022

10. Trinka E, Hofler J, Leitinger M, Brigo F. Pharmacotherapy for status epilepticus. Drugs. 2015. 75:1499-1521. DOI 10.1007/s 40265-015-0454-2

11. Trinka E, Hofler J, Zerbs A. Causes of Status Epilepticus. Epilepsia, 53(Suppl. 4):127-138, 2012. doi:10.1111/j.1528-1167. 2012.03622. $\mathrm{x}$

12. Rosenow F, Hamer HM, Knake S. The Epidemiology of Convulsive and Nonconvulsive Status epilepticus. Epilepsia 2007; 48:82-4. doi.org/10.1111/j.15281167.2007.01359.x

13. Legriel S, Brophy G. Managing status epilepticus in the older adult. J Clin Med 2016;5:53. doi.org/10.3390/ jcm5050053

14. Trinka E, Leitinger M. Which EEG patterns in coma are non-convulsive status epileptic? Epilepsy Behav2015;49:203-22. doi.org/ 10.1016/j.yebeh.2015.05.005

15. Ferlisi M, Shorvon S. Seizure precipitants in patients with epilepsy. Epilepsy Behav 2014;33:101-5. http://dx.doi.org/10.1016/ j.yebeh.2014.02.019.

16. Altındağ E, Erdoğan FF, Tezer İ, Özkara Ç. Management and Early Treatment of Status Epilepticus in Adults and Children. Turk J Neurol 2017;23:155-161. DOI:10.4274/tnd. 34635

17. Trinka E. Benzodiazepines used primarily for emergency treatment (diazepam, lorazepam and midazolam). In: Shorvon SD, Perucca E, Engel Jr J, (eds). Treatment of epilepsies. 3rd ed. Oxford: Blackwell Publishing, 2009:470-484.

18. Cereghino JJ, Cloyd JC, Kuzniecky RI; North American Diastat Study Group. Rectal diazepam gel for treatment of acute repetetive seizures in adults. Arch Neurol 2002; 59:1915-1920.

19. Trinka E, Höfler J, Zerbs A, Brigo F. Efficacy and safety of intravenous valproate for status epilepticus: a systemic review. CNS Drugs 2014;28:623-629.

20. Vezzani A, Dingledine R, Rossetti AO. Immunity and inflammation in status epilepticus and its sequelae: possibilities for therapeutic application. Expert Review of Neurotherapeutics. 2015;15:1081-1092.

21. Johnson EA, Guignet MA, Dao TL, Hamilton TA, Kan RK. Interleukin-18 expression increases in response to neurovascular damage following somaninduced status epilepticus in rats. J Inflamm (Lond). 2015 Jul 22;12:43.

22. Özdemir HH, Akil E, Acar A, Tamam Y, Varol S, Cevik MU, Arikanoglu A. Changes in serum albumin levels and neutrophillymphocyte ratio in patients with convulsive status epilepticus. Int J Neurosci. 2017 May;127(5):417-420. doi: 10.1080/00207454.2016.1187606. Epub 2016 May 24. PMID: 27161531.

23. Leitinger M, Kalss G, Rohracher A, Pilz G, Novak H, et al. Predicting outcome of status epilepticus. Epilepsy Behav. 2015. doi.org/10.1016/j.yebeh.2015.04.066

24. Rossetti AO, Logroscino G, Milligan TA, Michaelides C, Ruffieux C, et al. Status Epilepticus Severity Score (STESS): A Tool to Orient Early Treatment Strategy. J. Neurol. 2008.255, 1561-1566.

25. Sutter R, Kaplan P, Rüegg S. Outcome predictors for status epilepticus-what really counts. Nat. Rev. Neurol. 9, 525-534 (2013) doi:10.1038/nrneurol.2013.154

How to cite this article: Maria Oktaviany Gabur, I Wayan Widyantara, Anna M.G. Sinardja. Characteristics of patient with status epilepticus at the emergency department of Sanglah General Hospital. International Journal of Research and Review. 2021; 8(12): 211-217. DOI: https://doi.org/ 10.52403/ijrr.20211227 